\title{
Integrated magnetotelluric and seismic investigation of Cenozoic graben structure near Obrzycko, Poland
}

\author{
Adam Cygal $^{1}\left[\right.$ D $\cdot$ Michał Stefaniuk ${ }^{1} \cdot$ Anna Kret $^{2}$
}

Received: 18 September 2020 / Accepted: 29 December 2020 / Published online: 25 January 2021

(c) The Author(s) 2021

\begin{abstract}
This article presents the results of an integrated interpretation of measurements made using Audio-Magnetotellurics and Seismic Reflection geophysical methods. The obtained results were used to build an integrated geophysical model of shallow subsurface cover consisting of Cenozoic deposits, which then formed the basis for a detailed lithological and tectonic interpretation of deeper Mesozoic sediments. Such shallow covers, consisting mainly of glacial Pleistocene deposits, are typical for central and northern Poland. This investigation concentrated on delineating the accurate geometry of Obrzycko Cenozoic graben structure filled with loose deposits, as it was of great importance to the acquisition, processing and interpretation of seismic data that was to reveal the tectonic structure of the Cretaceous and Jurassic sediments which underly the study area. Previously, some problems with estimation of seismic static corrections over similar grabens filled with more recent, low-velocity deposits were encountered. Therefore, a novel approach to estimating the exact thickness of such shallow cover consisting of low-velocity deposits was applied in the presented investigation. The study shows that some alternative geophysical data sets (such as magnetotellurics) can be used to significantly improve the imaging of geological structure in areas where seismic data are very distorted or too noisy to be used alone
\end{abstract}

Keywords Magnetotellurics $\cdot$ Seismics $\cdot$ Glacial deposits $\cdot$ Comprehensive interpretation

\section{Introduction}

The article presents the results of multivariate analysis of geophysical data aimed at presenting the tectonic character and lithological composition of the Szamotuły tectonic trough in the vicinity of the Obrzycko town (Fig. 1). The first large-scale research work was carried out in this area as part of the project named "Improving the effectiveness of seismic surveys in the exploration and development of natural gas deposits in the Rotliegend Formations", where the main research issue was to explore the Szamotuły salt structure and to improve the seismic imaging of the sub-Zechstein formations. The research fieldwork included conducting a

Communicated by Michal Malinowski.

Adam Cygal

cygal@agh.edu.pl

1 Department of Fossil Fuels, AGH University of Science and Technology, Mickiewicza 30, 30-059 Cracow, Poland

2 PBG Geophysical Exploration Ltd., Wadowicka 8A, 30-415 Kraków, Poland seismic survey along the regional profile (named the Obrzycko-Zabartowo, AGH-2 profile), running through the analyzed area along the OZ3_2 magnetotelluric profile and magnetotelluric test studies.

A separate issue was to explore the structure and lithological changes within the subsurface zone, including seismic low-velocity zone and estimation of velocity distribution within this zone. This type of research is not directly related to the issue of the presence of geological horizons that strongly reflect seismic energy, but it does, apply in the correct implementation of static corrections during the seismic data processing stage. This problem becomes particularly important when the top of consolidated rocks is covered by a thick complex of younger loose sediments, which are characterized by high acoustic wave attenuation factor. Such a geometry of geological layers is typical for northern Poland, which is covered with a thick complex of sediments associated with the earliest stages of Pleistocene glaciations, under which there are often present poorly consolidated or even loose tertiary sediments. A similar sequence of sediments usually occurs also in the central part of the country in the area of the Polish Lowlands. As 
part of the above project, an attempt was made to analyze the geometry of the Szamotuły tectonic trough and the structure of the salt dome itself by means of seismic and magnetotelluric surveys implemented in two variants (MT and AMT). Proper identification of the geometry and velocity variations directly influenced the results of the estimation of refraction static corrections. Analyses carried out on other regional profiles, as part of this project, confirmed the existence of a strong impact of the presence of the trough on the acquisition and processing of reflection and refraction seismic data. At the seismic processing stage, it turned out that the method of combined inversion of reflection and refraction seismic data can be effectively applied in solving the issue of statics in such difficult research areas. Combined inversion of various geophysical data has so far been successfully used in 2D seismic profile data processing projects (Cygal et al. 2016, 2017a, b). Based on CSAMT studies, it has been proven that the evaporative sediments were located directly below the tertiary sediments. In order to perform a spatial analysis of the variability of geoelectric parameters, magnetotelluric measurements were carried out along four profiles (OZ3D_1, OZ3D_3, OZ3D_4 and OZ3D_5) laid out parallel to the AGH-2 seismic profile. These measurements were carried out within the project entitled: "Experimental and comprehensive multi-variant interpretation of seismic, magnetotelluric, gravity and borehole data as a tool to improve the efficiency of structural studies and deposit exploration". In total, 243 soundings were carried out both in the high-frequency AMT and low-frequency MT bands. The measurement points were located at intervals of $250 \mathrm{~m}$, in the central parts of the profiles, above the salt dome structure and at every $500 \mathrm{~m}$ on the ends of the profiles. Sounding intervals were designed based on the course of a tectonic trough marked on a geological map without the Quaternary formations (Dadlez et al. 2000). This approach was aimed at increasing the horizontal resolution in the discussed tectonic zone of Szamotuły. At each measurement point, two electrical components; Ex and Ey and three magnetic components; two horizontal $\mathrm{Hx}$ and $\mathrm{Hy}$ and one vertical $\mathrm{Hz}$, were simultaneously recorded using the Phoenix Geophysics Ltd equipment. Measurements were made with the reference point located in Zdory in Masuria, approximately $350 \mathrm{~km}$ from the study area. During the data acquisition phase, the recorded data were preprocessed in order to assess the quality of the obtained records. With a base station measurements are required to carry out Remote Reference Processing, which enables the elimination of electromagnetic interferences that adversely affect the recorded parameters (Gamble et al. 1979). The quality of the recorded data was generally high. The exception is several MT/AMT soundings carried out near the
Obrzycko-1 borehole, which were located in the zone of strong interference from the nearby electrified railway line.

\section{Geology}

The study area is covered with post-glacial deposits. In the substratum of extensive upland areas, deposits of direct accumulation of the glacier occur as clays, sandy clays and clayey sands, most often with a hard-plastic and semi-compact consistency (often with approximately 1-2 m thick layer of plastic and soft-plastic soils, in the groundwater zone). In many places, the tills are covered with a thin layer of flowing-water (glaci-fluvial and fluvial) sediments-layered sands and gravels. They are present, among others, in the area of the sandur (outwash) plain and within extensive terraces.

One of the elements of the geological structure that influences the results of geophysical surveys is the tertiary through - a complex block structure present in the study area (Fig. 3). It was created within the structure of Szamotuły in the vicinity of the Obrzycko town during the late Alpine tectonic events (the Savska, Styrian, Attic and Rhodian phases), when, in the Tertiary, the older dislocations in the substrata were reactivated. These were syn-sedimentation events; hence, the facies and thickness changes occur within individual tertiary sedimentary series. Some faults reaching the top of the Neogene were identified (Gogołek 1999; Szałajdewicz 2005; Krzywiec 2006). These SW-NE faults are perpendicular to the longer axis of the Mogilno synclinorium (Szałajdewicz 2005).

After the end of the Neogene sedimentation, the subQuaternary surface rose to a height of 40-60 m above sea level and was made of Poznań clays (Miocene-Pliocene) (Gogołek 1999; Widera 2019). The subsequent reliefshaping processes, mainly neotectonic events and glacial exaration (Szałajdewicz, 2005), lasted until the Middle Pleistocene and resulted in terrain height differences in the range of $210 \mathrm{~m}$ (present day height difference: $40 \mathrm{~m}$ ). It is an undulating topography, more varied in the western part of the area. The geological processes that took place within the study area during the Tertiary are presented in Table 1. After the sea receded, there was a period of prolonged denudation in the Paleogene. The re-entry of the sea in the Oligocene was associated with sedimentation in the coastal zone (sands, clays and glauconite silts). Gradually, along with the regression of the sea in the Upper Oligocene and later also in the Lower and Middle Miocene, there was an accumulation of clastic (sand, silt, clay) and organic sediments (later transformed into lignite) in the swamp environment and inland reservoirs. In the Upper Miocene and Pliocene, sedimentation of mineral deposits (Poznań clays) continued in the vast lake district. The 
Table 1 Fragment of the litho-stratigraphic table for the Paleogene and Neogene taken from the legend on the SMGP Parkowo geological map sheet (Szałajdewicz, 2005)

\begin{tabular}{lllll}
\hline Period & Epoch & Sub-epoch & Lithology & Geological Processes \\
\hline Neogene & Miocene-Pliocene & & Clays, silts and sands & Lake accumulation \\
& Miocene & Middle Miocene & Sands, silts, clays and brown coal (lignite) & $\begin{array}{l}\text { Lake and marsh accumulation with sea } \\
\text { ingressions. Lowering the Mesozoic } \\
\text { substratum. Further development of block } \\
\text { tectonics }\end{array}$ \\
& & & Sands, silts, clays and brown coal (lignite) & $\begin{array}{l}\text { Shallow sea transgression and sedimentation. } \\
\text { Development of fault tectonics in Alpine } \\
\text { Paleogene }\end{array}$ \\
& Oligocene & Clays, muds and glauconite sands & orogeny \\
\hline
\end{tabular}

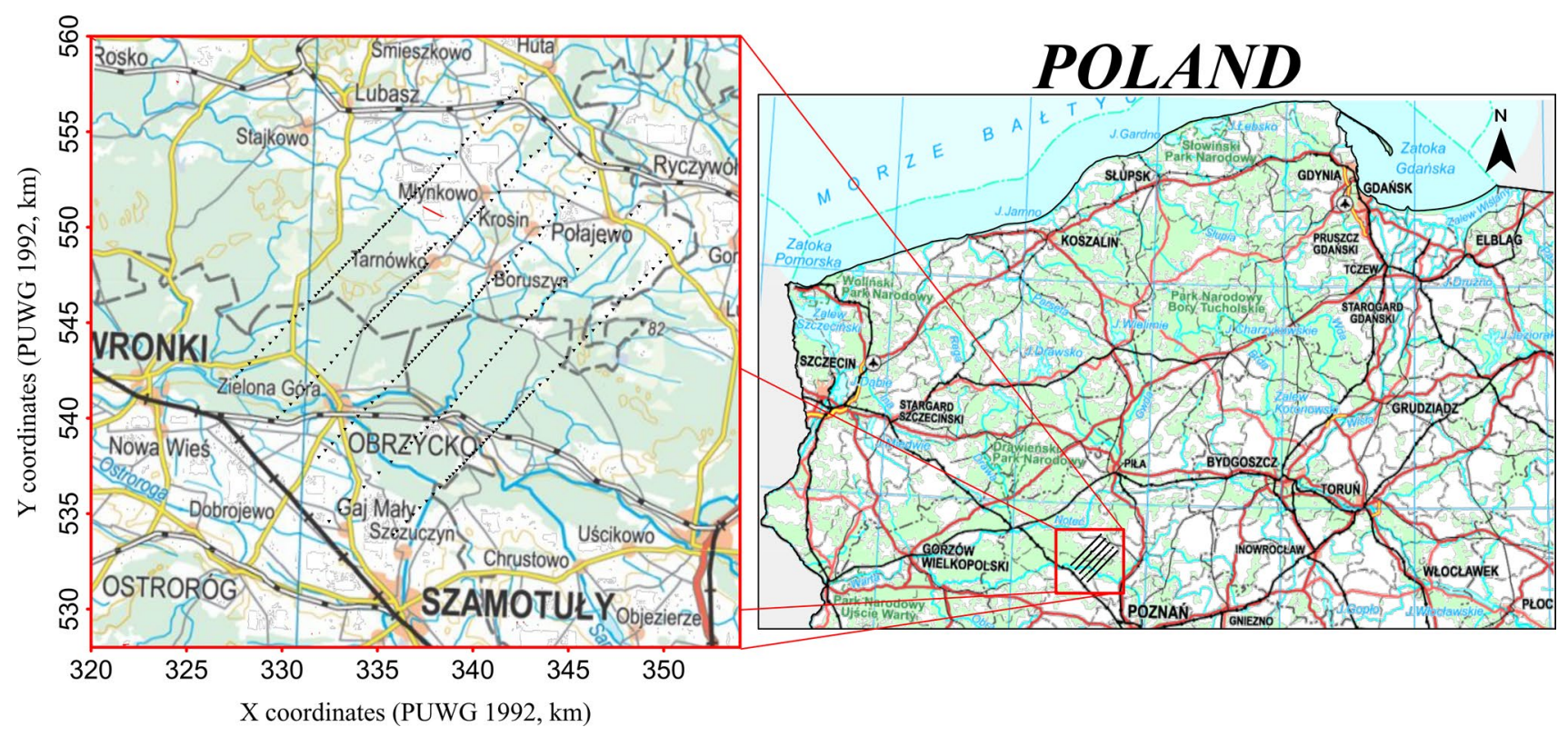

Fig. 1 Location map of geophysical surveys on the background of a topographic map (downloaded from the website https://mapy.geoportal.gov. p1/wss/service/pub/guest/ G2_SKOROWIDZE_TOPO/MapServer/ WMSServer on 01/08/2020)

Oligocene is represented by sandy, silty formations with glauconite and thin lignite layers. Their top was drilled through at the greatest depth in the zone of the Szamotuły tectonic trough and in the depressions on its limbs.

Also in this zone, the Oligocene series reaches its maximum thickness, up to $155 \mathrm{~m}$ (Gogołek 1999). The Miocene consists of sands, silts, clays and layers of lignite. The latter form thicker deposits within the tectonic throughs of the Szamotuły structure. Miocene outcrops on the sub-Quaternary surface are concentrated within the depressions in the Quaternary substratum, deeper valleys and fossil channels. The top of the Miocene series was mapped at heights from 20 to $145 \mathrm{~m}$ bsl, with the greatest thicknesses in the tectonic trough of the Szamotuly structure, even up to $135 \mathrm{~m}$ bsl (Gogołek 1999). The Miocene sediments consist of 4 series: bottom sands, lower lignite, upper sands and silts, upper lignite. In the Szamotuły trough, the lower lignite has the greatest thickness, on average $20 \mathrm{~m}$ (Skompski 1993). The Miocene and Pliocene (undifferentiated) sediments constitute the majority of the sub-Quaternary surface and are represented by clays and, in some places, silts and sands (lower and upper Poznań Beds). In the Boruszyn depression, the fossil valley of Samica and the fossil valley of Raduszyn, these sediments were eroded, while in the glaciotectonic disturbance zones they are located just below or are exposed on the surface (e.g. near Bąblin) (Gogołek 1999).

In the study area, the Pleistocene began with intense denudation processes during the South-Polish glaciation. The propagating ice sheet additionally increased the tertiary top surface leveling through glacial exaration, melting-water erosion and possible glaciotectonic disturbances. Quaternary sediments cover almost the entire surface of the study area. In the Boruszyn depression, their thickness is $211.5 \mathrm{~m}$ (NE part of the study area). They are represented by moraine, 
hydro-glacial and stagnant sediments of South-Polish, Central-Polish and the Baltic glaciations. According to the available information, there are no interglacial or interstadial organic deposits found in the study area. In the area of the Oborniki Wielkopolskie geological map sheet (SMGP) some organic sediments of the Eemian interglacial lakes occur.

The geophysical measurements are also greatly influenced by the sediments of the Permian-Mesozoic layer, which developed in the Polish Basin, known as the Mid-Polish Graben. It, in turn, was an element of the Permian-Mesozoic system of the epi-continental basins of Western and Central Europe (Fig. 4). Its development was conditioned by longterm thermal subsidy, which began in the Permian and continued until the early Cretaceous. Regional subsidence styles were locally modified by movements of salt structures that started in the early Triassic in the central (Kujawy) part of the graben (Krzywiec 2006). The final stage of development of the Mid-Polish Graben was the late-Turonian-Palaeocene inversion, ranging from 2500 to $3000 \mathrm{~m}$ and the formation of the Mid-Polish anticlinorium (Mid-Polish Horst). The remainder of its topographic relief was later reduced by erosion in the Eocene and completely leveled in the middle Oligocene. Long-term marine sedimentation with several short regressions and transgressions took place in the discussed study area from the lower Middle Jurassic to the Upper Jurassic (Maastrichtian). In the Lower Jurassic (Lias), in the shallow-water and delta environment, sandstones were formed, while in the Middle Jurassic (Dogger), along with the deepening of the basin, marine sedimentation, alternating with limnic, predominated. This led to the accumulation of black and brown claystones and mudstones. The Upper Jurassic shows the maximum of the Oxford transgression and the development of calcareous-dolomitic and marly sediments with ammonites (Szałajdewicz 2005). Cretaceous sediments lie unconformably on the Jurassic sediments as a result of the Young Kimmerian tectonic events. The Lower Cretaceous is represented by sandstones, sands, claystones and siltstones. In the Upper Cretaceous, there was a great marine transgression of the Cenomanian-Cenomanian formations are deposited on various stratigraphic units of the Jurassic and Cretaceous. From Turon to Santon, marine carbonate sedimentation with inoceramus prevailed and from Campanian to Maastrichtian - mainly marls. (Szałajdewicz 2005). The tectonic nature of the shallow zone associated with the uplift of the Jurassic and Cretaceous layers is illustrated by the map of Bouguer residual anomalies (Fig. 4b).

On the map of residual anomalies shown in Figure 5, the structure of Szamotuły, in the region of Obrzycko, manifests itself in the form of negative and positive band-shaped anomalies with amplitudes of up to $2 \mathrm{mGal}$ against the background of mutually intertwined anomalies of opposite signs with a typical local-anomaly character and small amplitudes, rarely exceeding $0.4 \mathrm{mGal}$. The background anomalies are distinguished by their irregular or oval shapes, often forming bands with various, usually disordered, axial directions. This type of gravity field indicates a relatively flat deposition of shallow Cenozoic-Mesozoic sediments and a low degree of their tectonic engagement, as well as a moderately diverse lithology. The above-mentioned narrow area of negative anomalies, between two parallel bands of positive values, extending from the vicinity of Poznań to the north-west, is caused by low-density sediments, including lignite intercalations, filling the tertiary tectonic through formed along the axis of the Szamotuły anticline. Its core is built of tectonically elevated Jurassic sediments and their top reaches the sub-Cenozoic surface. They are surrounded by younger Creataceous formations which are lighter than Jurassic ones and this causes a density contrast that generates gravity anomalies (Fig.5). Additionally, disturbances in the course of the anomaly band suggest the presence of faults having a strike-slip character.

\section{Methodology}

The presented results are based largely on magnetotelluric data processing outcome. The distribution of resistivity in a geological medium is usually complex in all three dimensions. The directions of homogeneity often change along the profile as well as vertically (for different registration frequencies). The 1D and 2D models are an acceptable simplification under certain conditions. The dimensionality of the medium (1D, 2D or 3D) also influences the choice of MT data interpretation methodology, therefore, skew and polar diagrams were evaluated.

The curves characterized by the lowest degree of interference were selected for analysis aimed at delineating changes in resistivity within the Szamotuły tectonic through. The frequency range corresponds to the AMT band falling between $1-10 \mathrm{kHz}$. In the process of quantitative interpretation of the AMT soundings recorded in the study area, 2D inversion modeling played a fundamental role, which was conditioned by the profile nature of the performed measurements. The quantitative interpretation was made based on algorithms for $1 \mathrm{D}$ and 2D inversion of magnetotelluric data. While 1D inversion was performed using Occam-type "smoothing" procedures(Constable et al. 1987), 2D inversion was performed according to the NLCG (Nonlinear Conjugate Gradients) algorithm (Rodi et al. 2001). The calculations were made using the WinGlink software.

The 1D inversion according to the Occam algorithm is a computer method for calculating the one-dimensional distribution of resistivity in a geological medium based on the amplitude and phase sounding curves (Constable et al. 1987). The basic assumption of this method is to achieve the most smooth (fluid) solution. As a result, the 
distribution of resistivity in the geological medium is generalized and devoid of any sharp contrasts. In practice, the computer program assumes a starting model in the form of a horizontally layered medium with the thickness of the layers increasing regularly with depth, in accordance with a logarithmic scale. The error function minimization procedure describing the discrepancy between the measured data and those calculated for the assumed model was constructed in such a way that the resistivity contrasts were minimal. As a result, for the a priori assumed number of layers in the starting model, their resistivity is subject to changes. The undoubted advantage of the method is its full automation. The interpreter's role comes down to data preparation, introducing the number of layers and defining the depth interval for the interpretation.

The NLCG method consists in iterative fitting of a twodimensional geoelectric medium to the amplitude and phase sounding curves, using the method of minimizing nonlinear coupled gradients (Rodi et al. 2001). The error function describing the total difference between the empirical and theoretically calculated data for the given model is minimized in subsequent iterative steps, leading to a gradual modification of the starting model. In its assumption, the NLCG method aims at a smooth model. The solution of the inversion problem is ambiguous, i.e. there are many different models that can be fitted to the given empirical data with a satisfactory accuracy (effect of equivalence). In this situation, it is important, in order to correctly use the program, to impose appropriate constraints making the obtained solution realistic and appropriate preconditions in the form of a starting model (Bujakowski et al. 2010; Oryński et al. 2019; Ślęzak et al. 2019). In the case of the conducted analyzes, it turned out that the best starting model for the 2D inversion according to the NLCG algorithm was the model built on the basis of the 1D inversion according to Occam's algorithm for all profiles. Curves for YX (TE-mode) polarization were used in the 1D Occam calculations. The introduction of a model that is close to the real one limits the range of its parameters' variability in the minimization process and usually leads to good solutions for shallow investigations (Oryński et al. 2019). The initial geometry of the medium was the model developed along the OZ3D-2 profile, which was located on the seismic line Obrzycko-Zabartowo (AGH-2). In this case, an additional factor improving the quality of the resulting model are constraints in the form of introduced constant values for the selected parameters or introducing limits on their variability range. For 2D NLCG inversion all available components YX (TE - mode), XY (TM - mode) and $\mathrm{Hz}$ (Tipper) were used. A good solution, especially for relatively flat geoelectric models, is to limit the variability of geoelectric layer parameters for those mesh elements, which include lithological boundaries interpreted based on the results of reflection seismic data processing (Dell'Aversana 2014; Stefaniuk et al. 2003, 2015).

The reinterpretation results of the gravity data from this region were included in the structural analysis. Based on the described computational methodology, geophysical crosssections presenting the distribution of the log resistivity values were prepared.

\section{Results}

Maps of residual anomalies developed on the basis of 2D frequency filtering with Butterworth filters for depth ranges 0-500 (Fig. 5a) and 0-1000 m (Fig. 5b) b.s.l. indicate the presence of geological structures with general NW-SE strike and with local changes in the value and / or direction of their strike. They can be identified with the transverse faults documented in this region, which are the remnants of the disrupting effects of the breaking up of Mesozoic deposits caused by the movement of salt structures underneath them. The maxima and minima of the anomalies are arranged along the geological units presented on the geological map of the Tertiary subsurface (Fig. 4a). The previously described strong positive anomalies related to the uplifted sediments of the Upper Jurassic (J3) are noteworthy and they can be observed in the presented geological cross-section. Unfortunately, the physical principles of gravity method are problematic in terms of the interpretation of gravity maps. The observed surface response of this method is the sum of the gravitational effects of all structural elements characterized by high density contrast. It is obvious that shallow deposits (e.g. sediments filling a tectonic trough) may have the greatest influence (Petecki et al. 1995), but in the described case the leading sources of anomalies are steeply inclined (uplifted) Upper Jurassic deposits with high volume densities. Nevertheless, these anomalies allow for mapping the direction and possible changes in the tectonic character of the central part of the Szamotuły trough. Moreover, these anomalies are an indicator of changes in the tectonic nature of salt structures and the direction of their migration. This phenomenon is apparent in the NW part of the research area. Considering the above-described ambiguities in this area, it was decided to perform magnetotelluric surveys along traverses that crossed the trough structure under almost straight angles. At locations where the recorded values of positive and negative gravity anomalies were elevated, the measurement interval was reduced to about $250 \mathrm{~m}$.

Detailed magnetotelluric studies were performed in order to identify the differentiation of the subsurface zone to a depth of several hundred meters and to identify the geometry of objects characterized by locally decreasing velocities with depth. As part of the interpretation of AMT data using the 2D inversion method, geoelectric models were developed 
along the magnetotelluric profiles. As a result of the calculations, cross-sections were obtained, on which, in general, two resistivity complexes could be distinguished. Below the higher-resistivity Quaternary and Tertiary deposits there are present low-resistivity Cretaceous formations and higherresistivity anomalies associated with the Cretaceous formations. On profiles OZ3D-2, OZ3D-3 and OZ3D-4, the distribution of resistivity in the Cretaceous and Jurassic formations reflects the deformation associated with salt tectonics processes. This fact was confirmed during previous surveys using the CSAMT method. Based on this method, it was possible to contour the subsurface resistivity relatively accurately.

Resistivity cross-sections, which were the final result of the geophysical interpretation, were then used for geological and tectonic interpretation based on magnetotelluric data. The analysis of the results was performed as a comprehensive interpretation together with the results of seismic and borehole data processing and, to a large extent, gravity data, which was described in previous chapters of this article (Fig. 4, Fig. 5). For the purposes of interpretation and spatial visualization of the resistivity distribution, some depth maps were prepared in the form of horizontal cross-sections at every $50 \mathrm{~m}$ for a total depth of 400 (Fig. 6, Fig. 7) and $500 \mathrm{~m}$ b.s.l. (Fig. 8).

The map presentation for shallow horizontal cross-sections (up to a depth of $100 \mathrm{~m}$ b.s.l) corresponds to the variability of the sediments within the Quaternary cover, which is largely in agreement with the elements of interpretation presented on the geological map of the subsurface zone
(Fig. 2). On the horizontal section at $50 \mathrm{~m}$ b.s.l. (Fig. 6b), it is possible to observe a high-resistivity anomaly with the WE strike corresponding to the delineated geological unit which is related to the accumulation of river sediments (units II and IV, Fig. 2). When analyzing the horizontal sections made for the greater depths, some elements related to the tectonics of the Szamotuly trough can be observed. Some high-resistivity NW-SE striking anomalies are apparent. In the western part, the high-resistivity anomaly is associated with sediments filling the so-called Boruszyn depression visible in the attached geological cross-section (Fig. 3) and characterized by an increase in the thickness of the Paleogene and Neogene sediments (right side). Moving deeper, the influence of the structural elements forming the Szamotuły trough is becoming even more apparent (Fig 7). Characteristic is also the low-resistivity anomaly related to the uplifted sediments of the low-resistivity Triassic formations from the south-west side (black arrows, Fig. 7). There are also high-resistivity anomalies present in the central part of the section (marked with blue arrows Fig. 7a) and they are related to the uplifted sediments of the Upper Jurassic and Lower Cretaceous, which is very well shown on the results of seismic data interpretation (Fig. 9). On this map, the tectonic outline of the trough can be clearly seen. The high-resistivity anomaly visible in the northern part of the area (Fig. 7) is probably related to the presence of higherresistivity carbonate-siliciclastic Upper Cretaceous sediments (Campan and Maastrichtian).

The analysis of the deeper parts of the studied medium presents a geoelectric image related directly to the elements

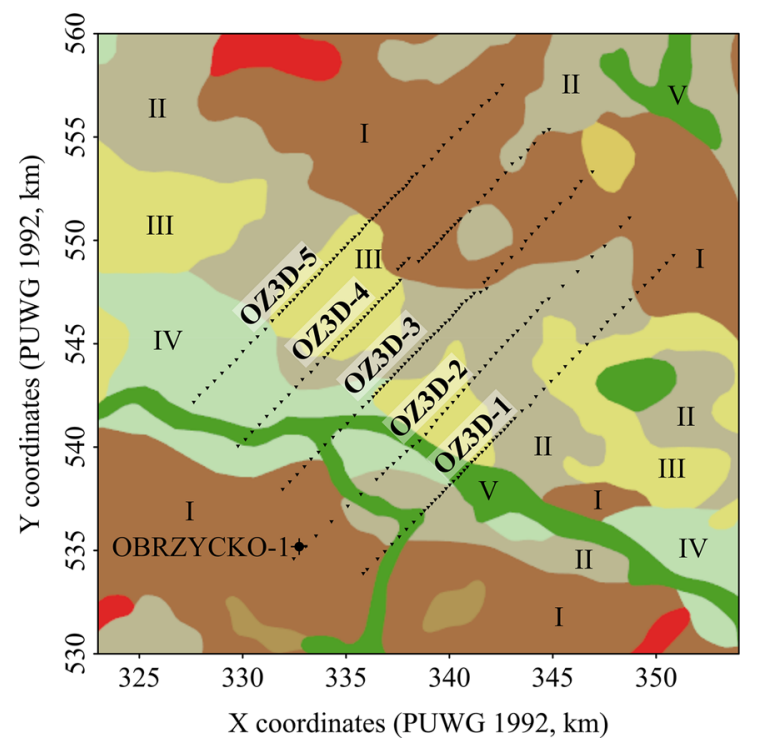

Legend:

I - Tills, weathered tills, glacial sands and gravels

II - Outwash sands and gravels

III - Eolian sands, locally in dunes

IV - Fluvial sands, gravels and silts

V - Fluvial sands, gravels, muds, peats and organic silts

Based on Geological map of Poland in 1:500 000

Source: Base of Polish Geological Institute - National Research https://geolog.pgi.gov.pl.

Fig. 2 Location of the survey area on the background of the geological map of Poland (1: 500000 scale) (downloaded from the website http:// cbdgmapa.pgi.gov.pl on 01/08/2020) 


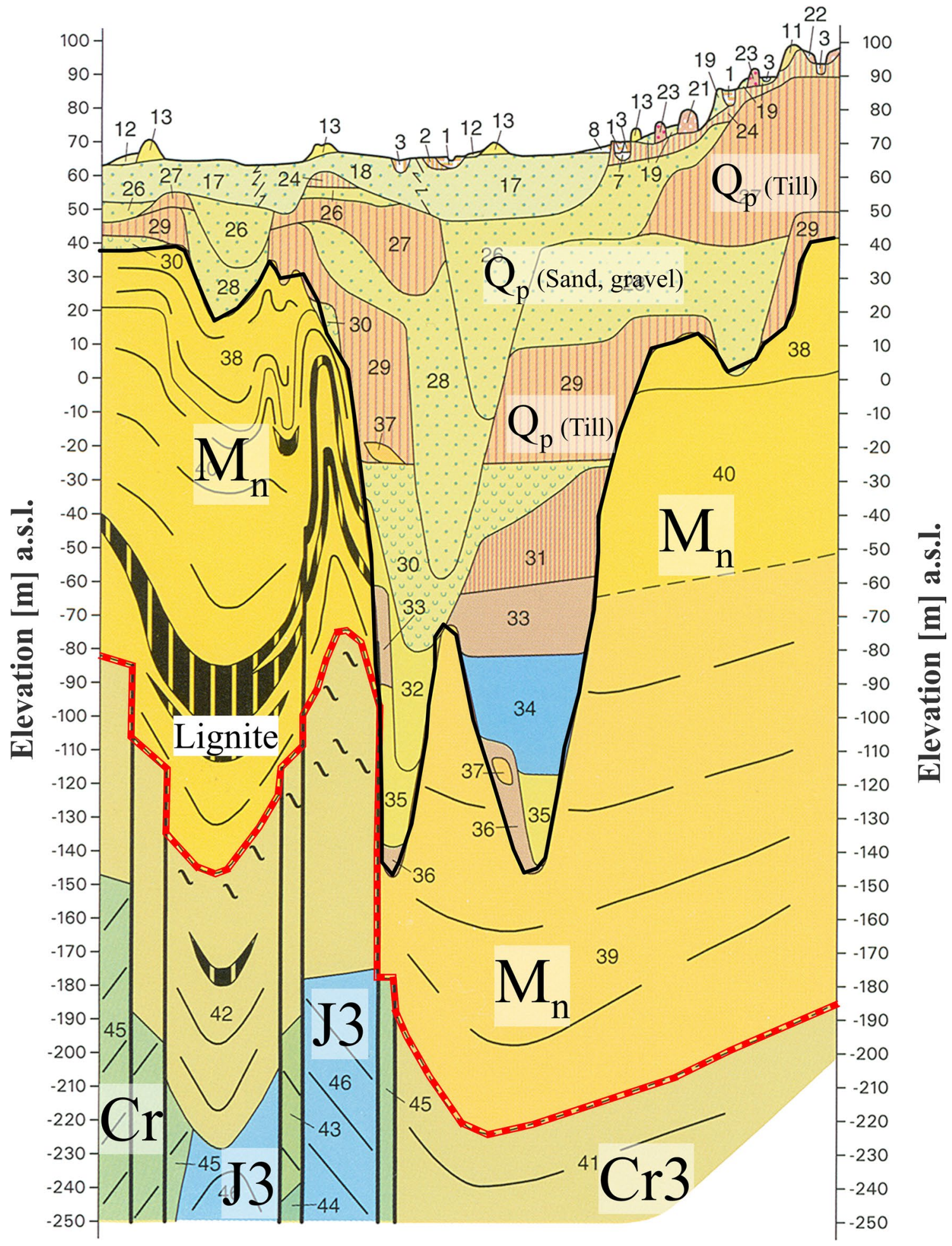

Fig. 3 Fragment of the geological cross-section for the Obrzycko map sheet (after Gogołek 1999)

which build the shallow Mesozoic substratum directly under the Szamotuły trough. The resistivity drop in the SE part of the trough (south of the marked fault according to
Dadlez (Dadlez et al. 2000) recorded in the central parts of the OZ3D-1 and OZD3D-2 profiles at a depth of 200 b.s.l. (red arrow, Fig. 6a) appears also quite interesting. This 


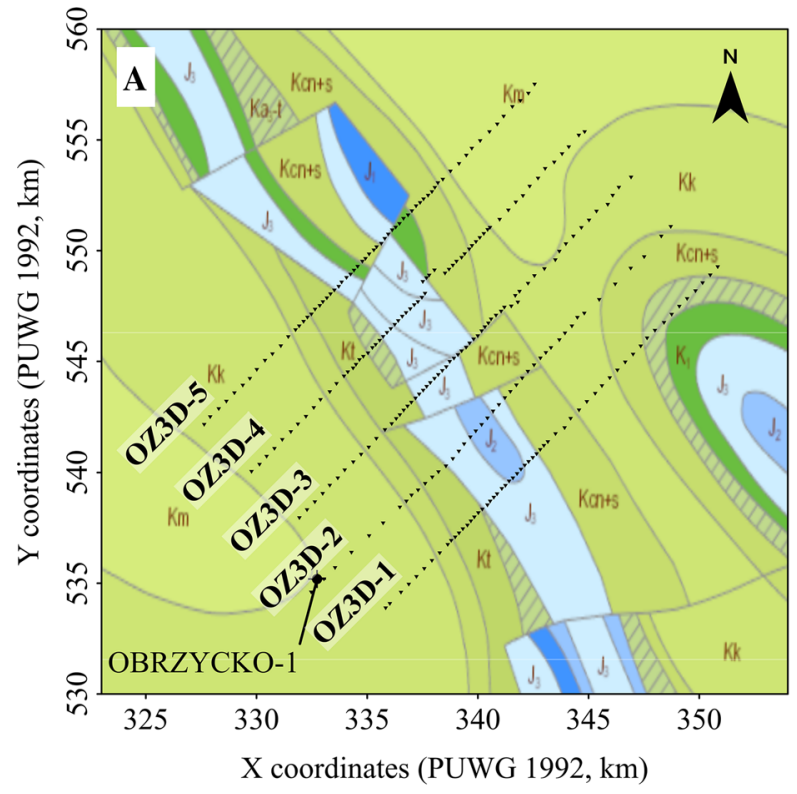

Fig. 4 a-Location of the study area on the background of the geological map of Poland without the Cenozoic formations, 1: 1000000 scale (Dadlez et al. 2000) (downloaded from the website http://cbdgm

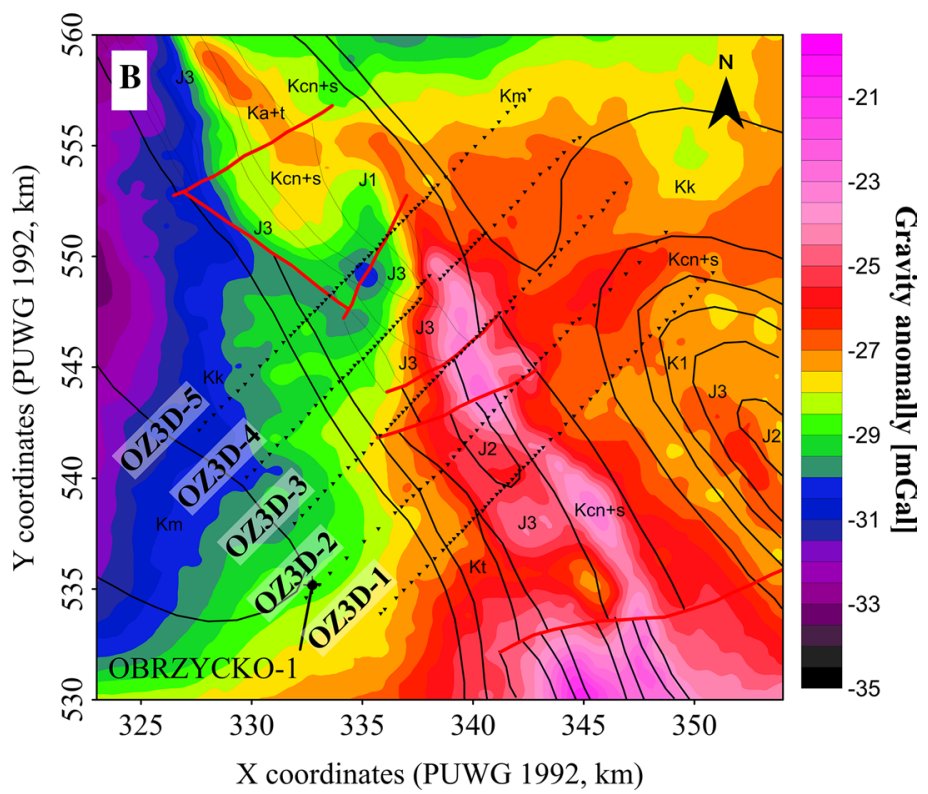

apa.pgi.gov.pl on 01/08/2020), (b) - Map of Bouguer gravity anomalies for the study area, after Polish Gravimetric Atlas (Petecki et al. 1995)

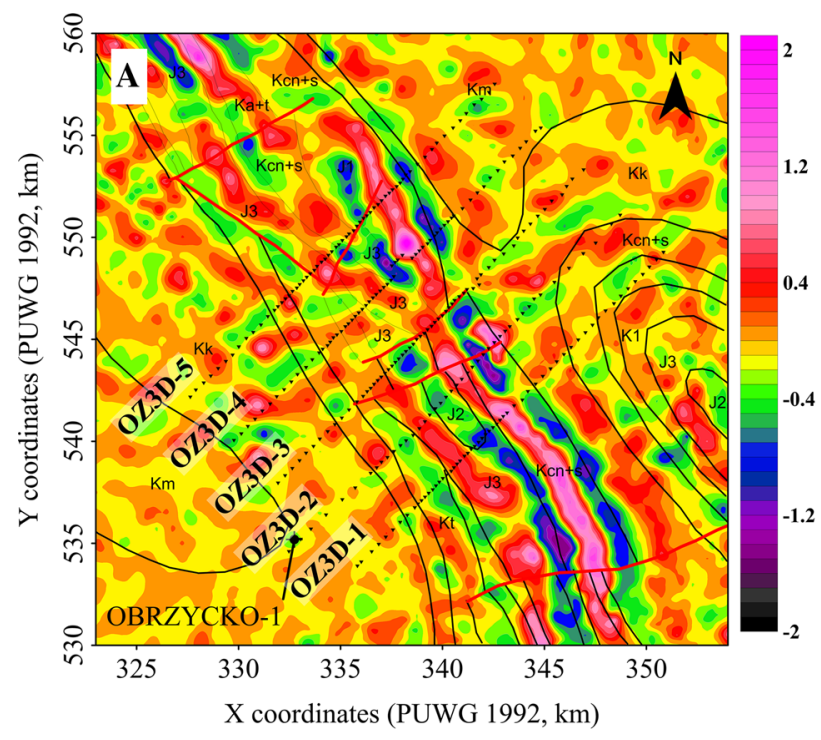

Fig. 5 Map of residual gravity anomalies $(0-1 \mathrm{~km})$ in the study area with marked elements of geological interpretation according to Dadlez (Dadlez et al. 2000) (a) —residual anomalies for the depth

indicates a change in lithology in this part of the structure. High-resistivity anomalies related to the deposits of the Upper Cretaceous are still observed. Their lateral extent is marked on the maps with dashed-line boundaries. The following figures (Fig. 7b, c and Fig. 8) present a picture of tectonic changes within the high-resistivity Jurassic and Cretaceous deposits, which are the effects of salt tectonics

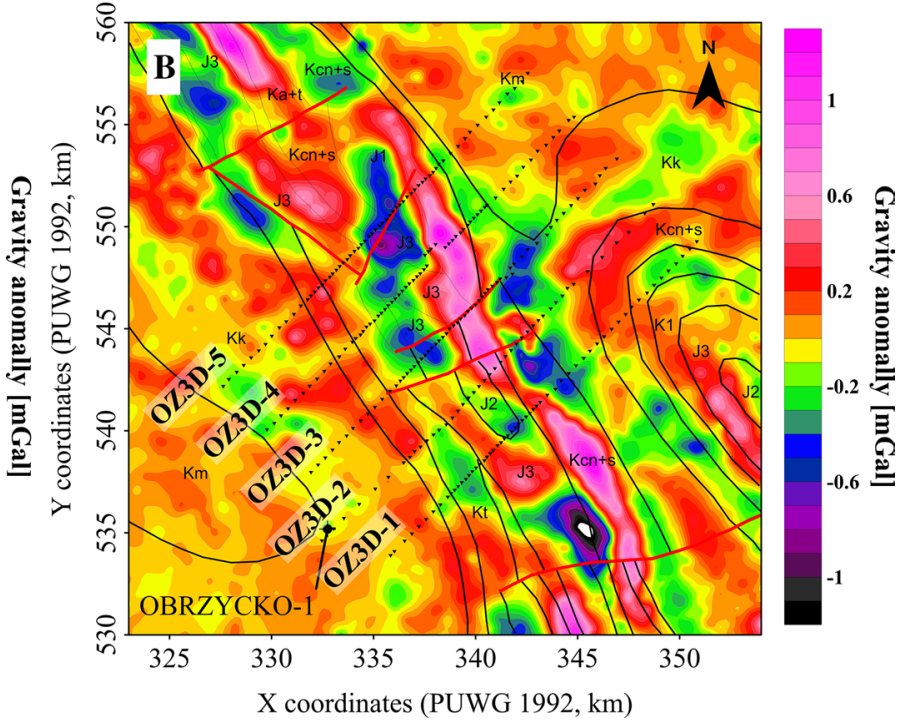

range $0-500 \mathrm{~m}$ b.s.l., (b) - residual anomalies for the depth range 0-1000 m b.s.l, after Polish Gravimetric Atlas (Petecki et al. 1995)

in this area (Widera et al. 2019; Rowan and Krzywiec 2014). It can be seen that the structure presented in the theoretical geological cross-section (Fig.3) is not a tectonic model for the entire area of the trough, which is confirmed in their analysis by Krzywiec (2006) and Widera (2019) and which is also apparent in the geophysical modeling of the subsurface zone carried out on the seismic regional 

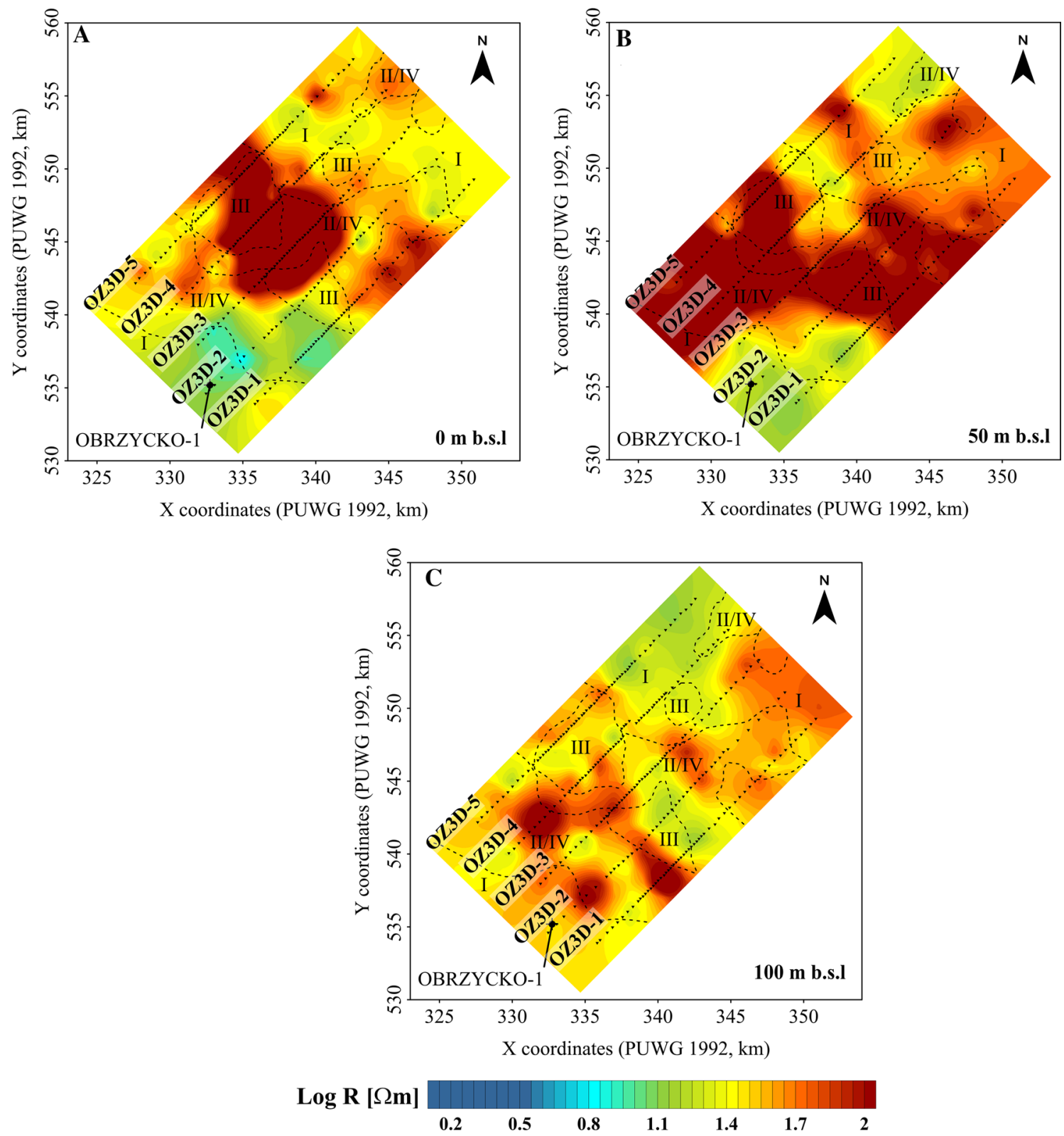

Fig. 6 Resistivity map based on 2D inversion of AMT data (using the NLCG algorithm); (a) - resistivity data at a depth of $0 \mathrm{~m}$ b.s.l. with elements of shallow interpretation based on the geological map of Poland (1: 500000 scale), (b) —resistivity data at the depth of $50 \mathrm{~m}$

profiles AGH-3 and AGH-4 (Cygal et al. 2017a, b; Cygal et al. 2016).

As can be seen in the part of the seismic section recorded along the OZ3D-2 (AGH-2) profile at a depth below $400 \mathrm{~m}$ bsl, the cap of "Szamotuły" salt dome (Rowan and Krzywiec 2014) is apparent in the Tertiary substratum (Fig. 9). The distribution of high-resistivity anomalies in the substratum (Fig. 7e and f) confirms the tectonic assumptions of the trough presence and is consistent with the current interpretations (Krzywiec 2006; Rowan and Krzywiec 2014). The resistivity b.s.l. with elements of shallow interpretation based on the geological map of Poland (1: 500000 scale), (c) — resistivity data at the depth of $100 \mathrm{~m}$ b.s.l. with elements of shallow interpretation based on the geological map of Poland (1: 500000 scale)

anomalies indicate that in the western part of the area (near the OZ3D-4 profile), the salt dome is divided into two parts (Fig. 7e and Fig. 8). 

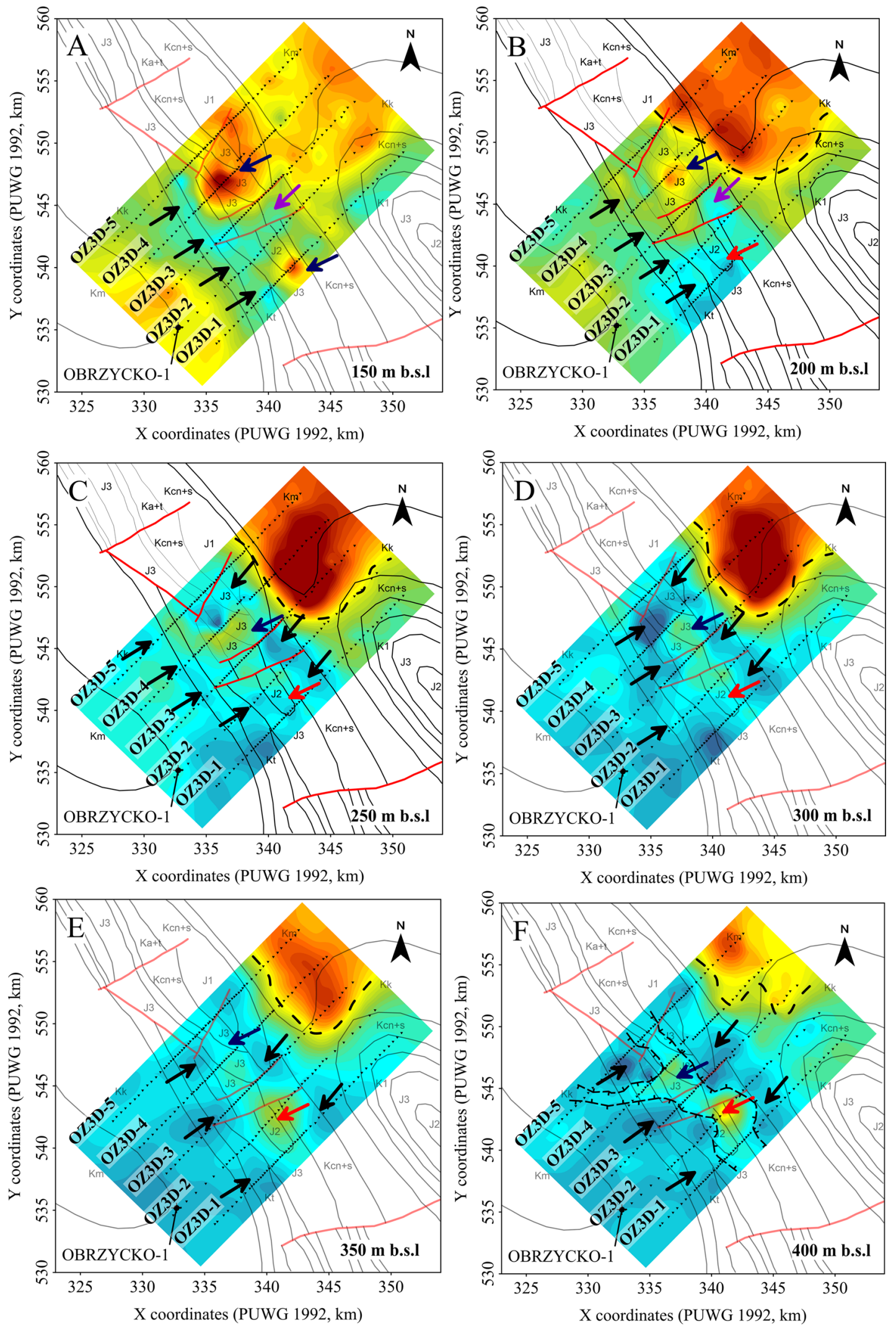

$\log R[\Omega m]$

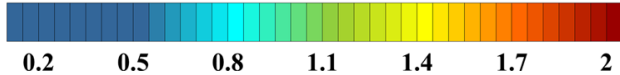


4Fig. 7 Resistivity map based on 2D inversion of AMT data (using the NLCG inversion algorithm); (a) -resistivity data at the depth of $150 \mathrm{~m}$ b.s.1., (b) - resistivity data at the depth of $200 \mathrm{~m}$ b.s.l., (c) resistivity data at the depth of $250 \mathrm{~m}$ b.s.l., (d) -resistivity data at the depth of $300 \mathrm{~m}$ b.s.l., (e) - resistivity data at the depth of $350 \mathrm{~m}$ b.s.l., B-resistivity data at the depth of $400 \mathrm{~m}$ b.s.l. with elements of deeper interpretation based on the geological map of Poland (1: 1000 000 scale)

\section{Summary}

From the point of view of conducting geological research, the magnetotelluric method provides a very wide depth penetration range. The drawback of this method, however, is its resolution which quickly decreases with depth, as a result of which anomalous objects of small dimensions become imperceptible at greater burial depths. Hence, in the natural field version (MT), this method is rather used for indirect exploration of the structure and lithological changes within the geological medium. (Golonka et al. 2009; Stefaniuk et. al 2003, 2018). For this reason, a highfrequency version of the AMT magnetotelluric method was selected for the development of the geoelectric geophysical model of the Szamotuły trough. The analysis of those maps made it possible to verify the tectonic genesis
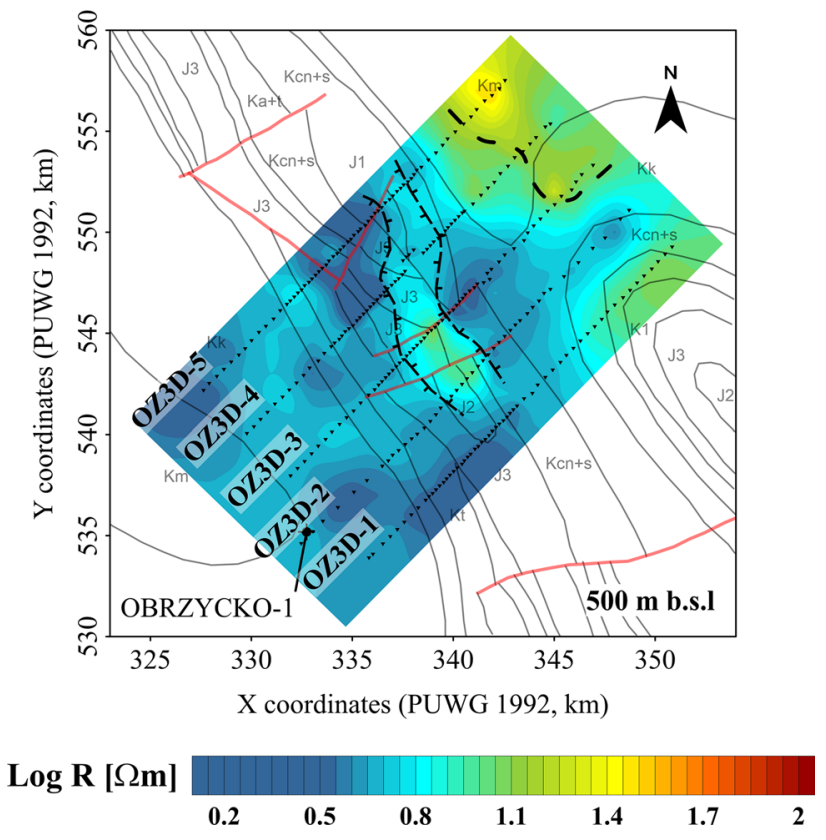

Fig. 8 Resistivity map based on 2D inversion of AMT data (using the NLCG inversion algorithm) at the depth of $500 \mathrm{~m}$ b.s.l. with elements of deeper interpretation based on the geological map of Poland (1: 1 000000 scale)
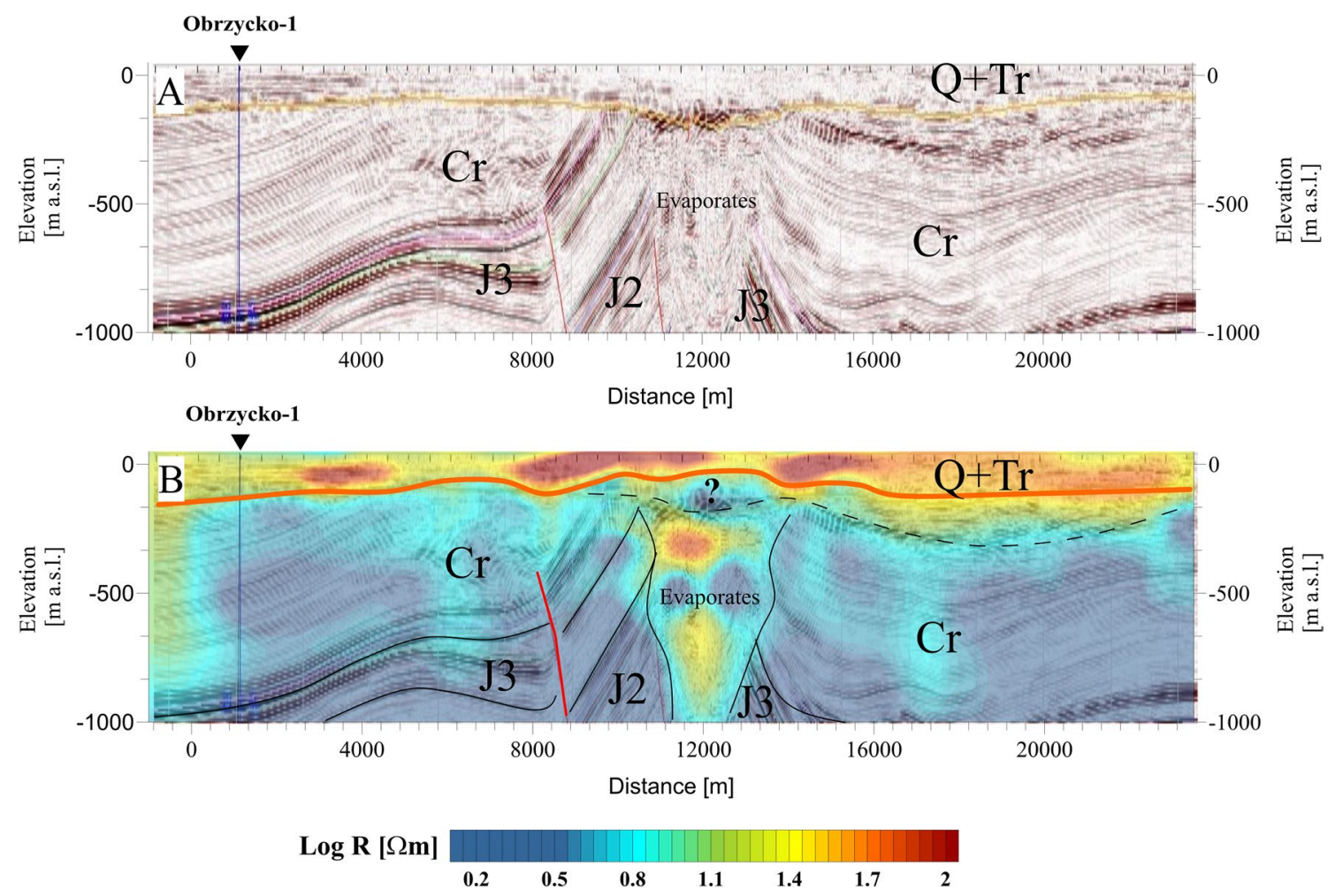

Fig. 9 a- Result of seismic processing along seismic profile AGH-2 (OZ3D-2) with interpretation, (b) - Comparison of seismic section and result of 2D inversion AMT data along magnetotelluric profile OZ3D-2 with interpretation 
of the tertiary tectonic trough of Szamotuły in the Obrzycko region. From the methodological point of view, the application of the magnetotelluric method provided a novel perspective on the possibilities of its future applications. Its application in this study directly enabled the lithological analysis of the sediments that build the trough and, to a slightly lesser extent, its geometry. In studies, where the leading exploration method is reflection seismics, the problem of strong acoustic wave scattering in the trough zone is observed. As a result, appropriate geological imaging is very difficult. Interpretation results based on non-seismic geophysical methods provide some additional information that is not always clear from the analysis of the seismic data itself (Dell'Aversana 2014; Cygal et al. 2016). At this point, it should be emphasized that the resolution of the seismic method cannot be undermined, but its interpretation based on comprehensive solutions can be supported. As it could be observed, the lower resolution results of gravity and magnetotelluric surveys carried information about the presence of geological boundaries with high density contrasts and the information about lithological changes in the case of geoelectric surveys. From the point of view of seismic data processing, this type of information is often not very obvious, e.g. due to incorrectly determined static corrections or complicated velocity analysis for data recorded in structurally complex regions like the presented one.

Acknowledgments The article was written as part of the following projects: PBSIII-"Experimental and comprehensive and multi-variant interpretation of seismic, magnetotelluric, gravity and borehole data as a tool to improve the effectiveness of structural and deposit exploration" No.: 19.19.140.87530, POIG 1.1.2-"Improving the effectiveness of seismic surveys in the exploration and development of natural gas deposits in the Rotliegend Formations" No.: 72.72.140.8425) and statutory grant No.: $16.16 .140 .315 / 05$.

\section{Compliance with ethical standards}

Conflict of interest On behalf of all authors, the corresponding author states that there is no conflict of interest.

Open Access This article is licensed under a Creative Commons Attribution 4.0 International License, which permits use, sharing, adaptation, distribution and reproduction in any medium or format, as long as you give appropriate credit to the original author(s) and the source, provide a link to the Creative Commons licence, and indicate if changes were made. The images or other third party material in this article are included in the article's Creative Commons licence, unless indicated otherwise in a credit line to the material. If material is not included in the article's Creative Commons licence and your intended use is not permitted by statutory regulation or exceeds the permitted use, you will need to obtain permission directly from the copyright holder. To view a copy of this licence, visit http://creativecommons.org/licenses/by/4.0/.

\section{References}

Bujakowski W, Barbacki A, Czerwińska B, Pająk L, Pussak M, Stefaniuk M, Trześniowski Z (2010) Integrated seismic and magnetotelluric exploration of the Skierniewice, Poland, geothermal test site. Geothermics The European I-GET Project Integrated Geophysical Exploration Technologies for Deep Geothermal Reservoirs. 39(1):78-93

Constable SC, Parker R, Constable CG (1987) Occam's inversion: A practical algorithm for generating smooth models from electromagnetic sounding data. Geophysics 52(3):289-300

Cygal A, Pilch J, Pasternacki A, Stefaniuk M, Maćkowski T, Ważny J (2017) Decreasing uncertainty of joint gravity and seismic inversion by constraining initial models with well and TEM data. 79th EAGE conference \& exhibition. https:// doi:https://doi. org/10.3997/2214-4609.201701299.

Cygal A, Pilch J, Stefaniuk M, Maćkowski T (2016) Application of joint inversion of seismic and gravity data for geological characterization of near surface zone. 22nd European meeting of environmental and engineering geophysics. https:// doi:https://doi. org/10.3997/2214-4609.201601943

Cygal A, Stefaniuk M, Kret A, Pilch J, Ważny J (2017) Identification of physical parameter variability in Pleistocene and Neogene sediment with the implementation of integrated geophysical data inversion. SGEM. https://doi:https://doi.org/10.5593/sgem2 017H/15/S06.030

Dadlez R, Marek S, Pokorski J (eds) (2000) Geological map of Poland without Cenozoic deposits at a scale 1:1 000 000. Warsaw, Polish Geological Institute

Dell'Aversana P (2014) Integrated Geophysical Models. Houten, EAGE, Combining Rock Properties with Seismic, Electromagnetic and Gravity Data

Gamble TD, Goubau WM, Clarke J (1979) Magnetotellurics with a remote reference. Geophysics 44:53-68

Gogołek W (1999) Objaśnienia do Szczegółowej mapy geologicznej Polski 1:50 000 Ark. Warszawa, PIG, Obrzycko, pp 1-40

Golonka J, Pietsch K, Marzec P, Stefaniuk M, Waśkowska A, Cieszkowski M (2009) Tectonics of the western part of the Polish Outer Carpathians. Geodin Acta 22(1-2):81-97

Królikowski C, Petecki Z (1995) Atlas grawimetryczny Polski. 1:500 000 i 1:750 000. Państwowy Instytut Geologiczny, Warszawa.

Krzywiec P (2006) Structural inversion of the Pomeranian and Kuiavian segments of the Mid-Polish Trough - lateral variations in timing and structural style. Geological Quarterly 50:151-168

Oryński S, Klityński W, Neska A, Ślęzak K (2019) Deep lithospheric structure beneath the Polish part of the East European Craton as a result of magnetotelluric surveys. Stud Geophys Geod 63:273289. https://doi.org/10.1007/s11200-017-1264-7

Rodi W, Mackie R. L (2001) Nonlinear conjugate gradients algorithm for 2-D magnetotelluric inversion. Geophysics. https:// DOI: https ://doi.org/10.1190/1.1444893.

Rowan M, Krzywiec P (2014) The Szamotuły salt diapir and MidPolish Trough: decoupling during both Triassic-Jurassic rifting and Alpine inversion. Interpretation.https://doi.org/10.1190/ INT-2014-0028.1.

Skompski S (1993) Objaśnienia do Szczegółowej mapy geologicznej Polski 1:50 000 Ark. Warszawa, PIG, Oborniki Wielkopolskie, pp 1-38

Ślęzak K, Jóźwiak W, Nowożyński K, Oryński S, Brasse H (2019) 3-D studies of MT data in the Central Polish Basin: Influence of inversion parameters, model space and transfer function selection. J Appl Geophys 161:26-36

Stefaniuk M (2003) Regionalne badania magnetotelluryczne w polskich Karpatach wschodnich. Geologia (kwartalnik AGH) 26:131-168 
Stefaniuk M (2020) Application of electromagnetic methods in recognizing of hydrogeothermal conditions inside crystalline massifs. Springer Nature Switzerland. Springer Proceedings in Energy. Renewable energy sources: engineering, technology, innovation. ICORES 2018:643-652

Stefaniuk M, Maćkowski T, Cygal A, Figuła J, Sada M (2015) Kompleksowa i zintegrowana interpretacja danych sejsmicznych i elektromagnetycznych w badaniach strukturalnych i poszukiwaniach naftowych - Complex and integrated interpretation of seismic and electromagnetic data in structural survey and oil prospection. Prace Naukowe Instytutu Nafty i Gazu ISSN 0209-072(198):231-235
Stefaniuk M, Maćkowski T, Sowiżdżał A (2018) Geophysical methods in the recognition of geothermal resources in Poland - selected examples. Springer International Publishing AG, cop. 2018. Springer Proceedings in Energy Renewable energy sources: engineering, technology, innovation : ICORES 2017:561-570

Szałajdjewicz J (2005) Objaśnienia do Szczegółowej mapy geologicznej Polski 1:50 000 Ark. Warszawa, PIG, Parkowo, pp 1-33

Widera M, Stawikowski W and Uścinowicz G (2019) Paleogene-Neogene tectonic evolution of the lignite-rich Szamotuły Graben. Acta Geologica Polonica. https:// DOI: https://doi.org/10.24425 lagp.2019.126439. 